\title{
Prevalence and Risk Factors of Hepatitis B infection in Pishin District, Pakistan
}

\author{
Sana Ullah ${ }^{1}$, Fauzia Asmat ${ }^{2}$, Mahrukh Naseem ${ }^{1 *}$, AsmatUllah Kakar ${ }^{1}$, ZafarUllah ${ }^{1}$, Jahangheer Khan $^{3}$ \\ ${ }^{1}$ Department of Zoology, University of Balochistan, Quetta-87300, Pakistan \\ ${ }^{2}$ Hayat Abad Medical Complex Hospital, Phase-4, Peshawar 25000-Pakistan \\ ${ }^{3}$ Center of Advanced Studies of Vaccinology and Biotechnology (CASVAB)
}

\begin{abstract}
DOI: $10.36348 /$ sijtcm.2021.v04i01.002
| Received: 08.01.2021 | Accepted: 19.01.2021 | Published: 30.01.2021
\end{abstract}

*Corresponding author: Mahrukh Naseem

\section{Abstract}

The hepatitis B virus (HBV) infection is life-threatening in developing countries associated with high morbidity and mortality rate. The current study designed to figure out the prevalence, socio-demographic variable and associated risk factors of HBV in the local population of Pishin District, Pakistan. Under the well-sterilized condition, blood samples of 1457 individuals were collected weekly from Civil Hospital Pishin, during May 2019 to February 2020 for the screening of HBV infection. Patients were categorized into 2 age groups i. e. 1-30 years, 31-60 years. The HBsAg was detected by a commercially available ELISA kit. The overall prevalence of HBV was $38.36 \%$. The incidence was higher in female $(22.30 \%)$ than in male patients $(16.06 \%)$. The socio-demographic finding showed that the prevalence was higher in patients with age group 31-60 years $(20.93 \%)$, in married $(30.19 \%)$, unvaccinated $(19,56 \%)$ individuals and with poor economic status (20.93\%). Furthermore, blood transfusion $(23.03 \%)$, surgery $(19.86 \%)$ and dental procedures $(12.70 \%)$ were the major risk factors associated with the high prevalence of HBV infection in Pishin. In conclusion, the Pishin District was highly prevalent with HBV infection. This study may serve as a guideline for the local health care providers to optimize the health facilities. By conducting the public health awareness program, it is possible to reduce the prevalence of $\mathrm{HBV}$ by minimizing the associated risk factors.

Keywords: HBV, Infection, Pishin, Prevalence, Risk factors.

Copyright (C) 2021 The Author(s): This is an open-access article distributed under the terms of the Creative Commons Attribution 4.0 International License (CC BY-NC 4.0) which permits unrestricted use, distribution, and reproduction in any medium for non-commercial use provided the original author and source are credited.

\section{INTRODUCTION}

Hepatitis B virus (HBV) infection is a global health issue. More than 350 million, individuals are found to be infected with this virus and about 60,000 deaths occur globally due to HBV. Moreover, HBV is the 10th leading cause of death globally $[1,2]$ and it is the main reason of liver cirrhosis and hepatocellular carcinoma [3]. Epidemiological study shows that there is a significant decline in the prevalence of $\mathrm{HBV}$ in developed countries due to proper vaccination and medical facilities, but unfortunately, in developing countries like Pakistan, its prevalence is very high due to lack of funding and precautionary measures for control this viral infection [4, 5]. In Pakistan, approximately 7-9 million carriers of HBV are present with a carrier rate of 3-5\% [2].

The HBV has a negative influence on the patient's psychological status via certain pathways. As HBV can be spread in the common population, so the patients are susceptible to suffer from disgrace and discriminated attitude [6], resulting in a negative social response [7]. The HBV patients experience loneliness, desperateness leading to an increased vulnerability to anxiety [8]. Low socioeconomic status and lack of awareness about the risk factors for disease transmission play a significant role in the spread of HBV infection. Several risk factors such as ear/body piercing, tattoo, blood transfusion, reuse of syringes, barbershops, surgical and dental equipment are reported to be associated with the spread of HBV infection [9].

In general, limited data is available on prevalence and etiology of $\mathrm{HBV}$ in Balochistan province and not even a single study has been published about the cases in the local population of Pishin District. Therefore, the present study aims to determine the prevalence of $\mathrm{HBV}$ infection in the local population of Pishin. The socio-demographic variables associated with the prevalence and possible risk factors for transmission in the local population of Pishin were also addressed since these variables are very essential for designing the strategies to control the disease. Furthermore, this study will help the general population 
to increase the knowledge about disease transmission so that new cases could be prevented.

\section{MATERIALS AND METHODS Study Design}

A survey was conducted in Civil Hospital Pishin, Balochistan during May 2019 to February 2020 in order to collect a data HBV patients' age among 1-60 years. The complete history of the patients was taken from their consultants. Participants having less than 1 year of age and greater than 60 years of age were excluded from the study. The socio-demographic data (age, gender, marital status, vaccination history, education status, occupation, history of blood transfusion etc) were obtained from patients' charts. The data of associated risk factors were also collected in our questionaries' based study from the patients/guardian. In total 1457 blood samples were collected for the screening of HBV infection among which 771 were females and 686 were males. Patients were categorized into 2 age groups as follows: 1-30 years, 31-60 years.

\section{Laboratory Examination}

Under well-sterilized conditions, $5 \mathrm{ml}$ venous blood was collected in a plastic tube without anticoagulant serum was separated by following the laboratory protocol and stored at $-20^{\circ} \mathrm{C}$ in the eppendorf tubes until tested for HBV. HBsAg was detected using third-generation commercially available ELISA kits. Data were entered on GraphPad Prisim Version 6 (IBMP Crop, USA) for analysis and graph preparation.

\section{RESULTS}

\section{Overall Prevalence and socio-demographic} characteristics of $\mathrm{HBV}$ infection

During the period of 10 months from May2019 to February 2020, 1457 individuals were screened for HBV infection and $559(38.36 \%)$ positive cases were reported in the local population of Pishin District. The overall incidence was found higher in females $22.30 \%(325 / 1457)$ than in males $16.06 \%$ (234/1457) (Figure-1). The prevalence, of HBV, was found to be higher in the age group 31-60 yrs both in the female $12.29 \%(179 / 1457)$ and male $8.64 \%$ (126/1457) patients as compared to 1-30 yrs (Figure-2). Several socio-demographic variables associated with the prevalence of HBV infection are given in Table-1. The overall, prevalence was found high in 31-60yrs $(20.93 \%)$ of individuals. High prevalence was recorded in married individuals (30.19\%). The HBV infection was strongly associated with vaccination and monthly income. The high rate of HBV infection, was observed in unvaccinated $(19.56 \%)$ patients and those with poor economic status $(20.93 \%)$. We found a negligible association between the prevalence of $\mathrm{HBV}$ with education and occupation.

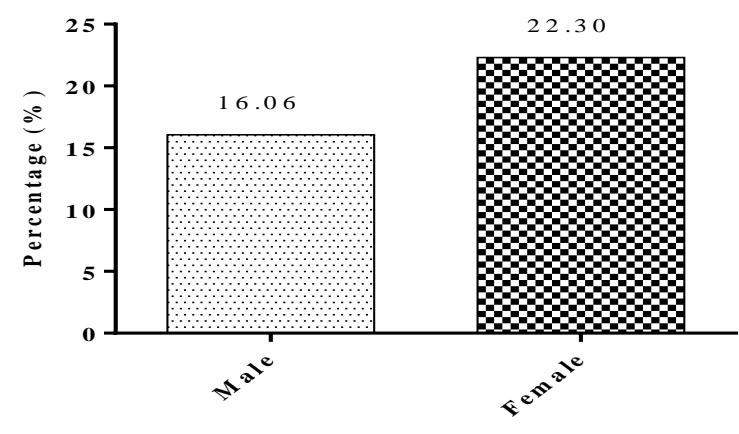

Fig-1: Gender wise prevalence of $\mathrm{HBV}$ patients in Pistin District

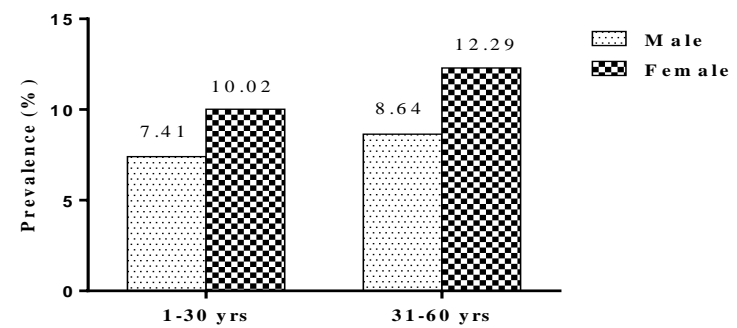

Fig-2: Age wise prevalence (\%age) of Male and Female HBV patients in Pishin District

Table-1: Socio-demographic factors associated with the prevalence of $\mathrm{HBV}$ infections in Pishin District

\begin{tabular}{|l|l|l|}
\hline Characteristics & Frequency & \%age \\
\hline Age & 254 & \\
1-30 yrs & 305 & \\
31-60 yrs & & 7.43 \\
& & \\
& & 0.93 \\
\hline Marital Status & 119 & \\
Unmarried & 440 & 8.17 \\
Married & & 30.19 \\
\hline Vaccination & 285 & \\
Un-vaccinated & 176 & 19.56 \\
Vaccinated & 98 & 12.07 \\
Partial vaccinated & & 6.73 \\
\hline Education Status & 114 & \\
Illiterate & 76 & 7.82 \\
Primary & 98 & 5.22 \\
Secondary & 72 & 6.73 \\
Intermediate & 139 & 4.94 \\
Graduate & 60 & 9.54 \\
Masters & & 4.11 \\
\hline Monthly income & 305 & \\
Less than 10,000 & 139 & 20.93 \\
10,000 - 30,000 & 59 & 13.84 \\
More than 30,000 & 56 & 13.24 \\
Depend on parents & 194 \\
\hline Occupation & 193 \\
Unemployed & & \\
Employed & & \\
Self-business & & \\
\hline & & \\
\hline
\end{tabular}

\section{Risk factors for $\mathrm{HBV}$ infection}

Blood transfusion $(23.07 \%)$, surgery $(19.86 \%)$ and dental procedures $(12.70 \%)$ were the main risk factors of $\mathrm{HBV}$ infection. In males, barber shops 
$(10.02 \%)$ were the other major route for the transmission of this viral infection as barbers reused the single razor. On the other hand, accidents $(4.29 \%)$ and infected mother to a newborn baby $(8.59 \%)$ were reported to be the least possible sources of infection (Figure-3).

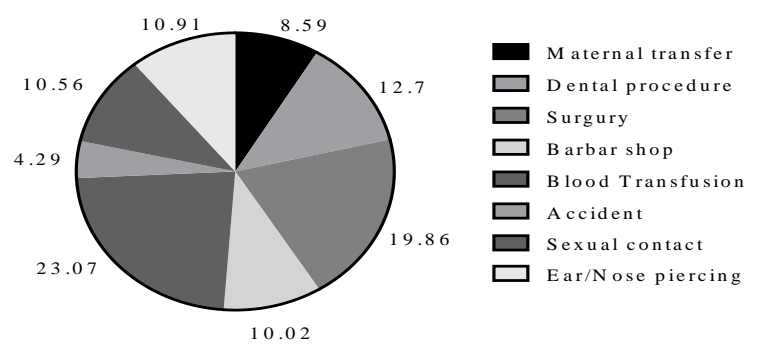

Fig-3: Risk factors among HBV seropositive individuals in Pishin District

\section{DISCUSSION}

The HBV infection is life-threatening in developing countries associated with high morbidity and mortality rate [10]. The HBV is increasing at an alarming rate and it is the main cause for silent contagious liver infection as well as certain other serious health issues. Its prevalence is increasing from $2-8 \%$ in different population groups globally and the situation in Pakistan is not different from the rest of the world [11]. Particularly, in underdeveloped countries including Pakistan the acute hepatitis B patients are at high risk to develop the chronic liver disease [12]. The high incidence of $\mathrm{HBV}$ infection in South Asian countries are attributed to poorly screened blood transfusion, re-use of contaminated syringes, lack of pre-marriage test, limited health facilities, and delay improper way of vaccination [13].

Certain risk factors are highly associated with the spread of this chronic viral infection. Thus, it is very important to find the risk factors associated with the transmission of $\mathrm{HBV}$, vaccination status, early diagnosis and treatment [14]. To measure the prevalence and assessing the risk factors associated with HBV infection, the current study was conducted.

The results of the present study revealed that the prevalence of HBV infection in Pishin is $38.36 \%$ which means that Pishin had high HBV endemicity, besides this, we also found a high rate of HBV in 31-60 yrs of age group. Previously, Sheikh and co-workers [12] reported HBV infection in some interior areas of Balochistan province and reported HBV as low as 3.3\% in Khuzdar to as high as $17 \%$ in Kodi Zikriani, but they do not include the Pishin District in their study. In another study by Marri and Ahmed [15], reported $11 \%$ prevalence of HBV in Quetta city. Furthermore, a high prevalence was found in the 31-60 years of age group and the high rate was found in married individuals than unmarried. The exact reasons responsible for having the majority of chronic HBV infections in people having age more than 30 years is not known, but it is assumed that re-use of needles, unscreened blood transfusions, tattoo, sexual transmission are some of the common ways to spread infections [12], as also explored in the interview with the patients in this study.

Our findings indicated the high prevalence of HBV infection in married couples which might be due to transmission of $\mathrm{HBV}$ from their life partners due to sexual contact since there is no trend to do pre-marriage diagnostic tests in Pakistan. Previously many researchers found high $\mathrm{HBV}$ percentage in male individuals [16, 17], but we found a higher female to the male ratio which might be due to poor compliances to hygiene and aseptic practices during delivery and Csection procedures.

The individuals with low socioeconomic were more prone to HBV infection and these results coincide with the previous studies [16, 18]. We further found that many patients never experienced the vaccination of HBV throughout their life because unawareness or may have certain misperceptions about it. Furthermore, considerable positive HBV cases were found in vaccinated individuals as well, which might be due to poor compliance in vaccination. The low level of knowledge about the disease and its vaccination is also reported previously from different parts of the country $[17,19]$. According to our findings, educational status does not show any influence on HBV infection but, HBV was found high among illiterate people. We also noticed that the hygiene condition of educated individuals was better than illiterate or low educated individuals. Educated persons have better awareness than illiterate individuals, maintain good personal hygiene condition and can take good care against the certain pathogen [20].

Recognizing risk factors for $\mathrm{HBV}$ infection is crucial for the development of control measures. Several studies have shown that sexual contact, maternal transfer, ear/nose piercing are the main risk factors for HBV infection [1, 21]. But we found that blood transfusion, surgical and dental equipment is the main mode of transmission for this virus. Many other researchers' previously also studied the risk factors of HBV $[3,5,11]$. In highly endemic areas like Southeast Asia and Africa, the most common mode of transmission is from $\mathrm{HBV}$-infected mother to the newborn as also reported in the present study $[1,8]$.

\section{CONCLUSION}

In conclusion, we found the high prevalence of HBV in Pishin, and we also found a strong association of HBV infection with age, sex and marital status. Likewise, a significant relationship of $\mathrm{HBV}$ was found with blood transfusion, surgery and dental procedures. It is vital to arrange some awareness seminars for the general public about the risk factors of HBV. However, it is recommended that a catch-up vaccination program 
must be implemented as a strategy program which will enhance the control of HBV infection and transmission.

\section{REFRENCESS}

1. Janahi, E. M. (2014). Prevalence and risk factors of hepatitis B virus infection in Bahrain, 2000 through 2010. PloS one, 9(2), e87599.

2. Ahmad, F., Rehman, M. U., Jadoon, M. A., Hayat, A., Khan, I., \& Ullah, R. (2017). Prevalence of Hepatitis B and C Infection in Havelian City, Khyber: Pakhtunkhwa, Pakistan. J Ent Zool Stud, 5, 1024-1026.

3. Butt, A. S. (2015). Epidemiology of viral hepatitis and liver diseases in Pakistan. Euroasian journal of hepato-gastroenterology, 5(1), 43.

4. Aftab, M., Amin, I., Idrees, M., Ali, A., Rafique, S., \& Naz, S. (2018). Molecular epidemiology of hepatitis delta and hepatitis B viruses circulating in two major provinces (East and North-West) of Pakistan. Infection, Genetics and Evolution, 64, 65-69.

5. Butt, N., Khan, M. A., Haleem, F., Butt, S., Reema, S., Qureshi, T., \& Abbasi, A. (2019). Epidemiology, Clinical Characteristics, and Management Status of Hepatitis B: A Crosssectional Study in a Tertiary Care Hospital at Karachi, Pakistan. Cureus, 11(1). e3880.

6. Huang, J., Guan, M. L., Balch, J., Wu, E., Rao, H., Lin, A., ... \& Lok, A. S. (2016). Survey of hepatitis B knowledge and stigma among chronically infected patients and uninfected persons in Beijing, China. Liver International, 36(11), 1595-1603.

7. Liu, Y., Tang, K., Long, J., \& Zhao, C. (2017). The association between hepatitis B self awareness and depression: Exploring the modifying effects of socio economic factors. Journal of viral hepatitis, 24(4), 330-336.

8. Vu, T. T. M., Le, T. V., Dang, A. K., Nguyen, L. H., Nguyen, B. C., Tran, B. X., ... \& Ho, R. (2019). Socioeconomic vulnerability to depressive symptoms in patients with chronic hepatitis B. International journal of environmental research and public health, 16(2), 255.

9. Kumar, T., Zada, S., Irfan, M., Batool, H., \& Sajjad, W. (2020). Serological Prevalence of Hepatitis B Virus in Peshawar, Khyber Pakhtunkhwa, Pakistan. Pakistan Journal of Zoology, 52(2), 525.

10. Ataei, B., Alavian, S. M., Shahriari-Fard, F., Rabiei, A. A., Safaei, A., Rabiei, A., \& Ataei, M. (2019). A case-control study of risk factors for hepatitis B infection: A regional report among Isfahanian adults. Journal of research in medical sciences: the official journal of Isfahan University of Medical Sciences, 24.

11. Ahmed, A., Aziz, M. O., Mohammad, I., uz Zaman, A., Akram, R., Javed, S., \& Aziz, A.
(2017). Prevalence of hepatitis B and C in patients admitted in orthopedics department of Ghurki Trust Teaching Hospital, Lahore, Pakistan. Rawal Medical Journal, 42(4), 455-458.

12. Sheikh, N. S., Sheikh, A. S., Sheikh, A. A., \& Yahya, S. (2011). Sero-prevalence of hepatitis B virus infection in Balochistan Province of Pakistan. Saudi Journal of Gastroenterology: Official Journal of the Saudi Gastroenterology Association, 17(3), 180.

13. Lai, C. L., Chien, R. N., Leung, N. W., Chang, T. T., Guan, R., Tai, D. I., ... \& Gray, D. F. (1998). A one-year trial of lamivudine for chronic hepatitis B. New England Journal of Medicine, 339(2), 6168.

14. Keshavarz, K., Kebriaeezadeh, A., Alavian, S. M., Sari, A. A., Dorkoosh, F. A., Keshvari, M., ... \& Nikfar, S. (2015). Economic burden of hepatitis B virus-related diseases: evidence from iran. Hepatitis monthly, 15(4): e25854..

15. Marri, S. M., \& Ahmed, J. (1997). Prevalence of hepatitis B antigenaemia in general population of Quetta, Balochistan. Biomedica, 13(2), 51-2.

16. Hassan-Gillani, A., Hayat, K., Ahmed, A. B., Asif, M., \& Azam, A. (2019). Evaluation of knowledge about hepatitis $\mathrm{B}$, its vaccination and its correlation with the vaccination status of the general population in Bahawalpur, Pakistan. Medicina Universitaria, 21(3), 105-112.

17. Ullah, H., Ullah, A., \& Khan, M. W. (2020). 46. Assessment of factors affecting and causing Hepatitis B in Balochistan-Pakistan. Pure and Applied Biology (PAB), 9(1), 471-477.

18. Cheung, J., Lee, T. K., Teh, C. Z., Wang, C. Y., Kwan, W. C., \& Yoshida, E. M. (2005). Crosssectional study of hepatitis B awareness among Chinese and Southeast Asian Canadians in the Vancouver-Richmond community. Canadian Journal of Gastroenterology, 19, 245-249.

19. Hu, Y., Chen, Y., Guo, J., Tang, X., \& Shen, L. (2014). Completeness and timeliness of vaccination and determinants for low and late uptake among young children in eastern China. Human vaccines \& immunotherapeutics, 10(5), 1408-1415.

20. Kim, S. J., Han, K. T., Lee, S. Y., \& Park, E. C. (2015). Quality of life correlation with socioeconomic status in Korean hepatitis-B patients: a cross sectional study. Health and quality of life outcomes, 13(1), 55.

21. Ximenes, R. A., Figueiredo, G. M., Cardoso, M. R. A., Stein, A. T., Moreira, R. C., Coral, G., ... \& Pereira, L. M. (2015). Population-based multicentric survey of hepatitis B infection and risk factors in the north, south, and southeast regions of Brazil, 10-20 years after the beginning of vaccination. The American journal of tropical medicine and hygiene, 93(6), 1341-1348. 